\title{
LEITURA DA CRIAÇÃO: OS MANUSCRITOS LITERÁRIOS COMO UM SISTEMA COMPLEXO
}

\section{THE READING OF CREATION: THE LITERARY MANUSCRIPTS AS A COMPLEX SYSTEM}

\section{Sergio Romanelli \\ Universidade Federal de Santa Catarina}

RESUMO: Neste artigo apresento o paradigma emergente da ciência contemporânea e a noção de sistema, mostrando como tais princípios podem ser aplicados à analise de textos e manuscritos literários. Desejo indagar como os métodos da assim chamada ciência da complexidade podem ser aplicados aos estudos do processo de criação literária. Considero a escrita como um sistema complexo, que se caracteriza por três pressupostos: da complexidade, da instabilidade e da intersubjetividade. Desejo ainda demonstrar como o pensamento sistêmico aplicado ao estudo dos manuscritos literários, não somente permite localizar, estudar e processar as leis e recorrências que regem tais processos, mas, sobretudo, ajuda a destacar o papel dos criadores. PALAVRAS-CHAVE: Pensamento sistêmico. Manuscritos literários. Processo criativo.

ABSTRACT: In this paper I present the emerging paradigm of the contemporary science, together with the notion of system, in order to understand how such principles can also be applied to the study of literary manuscripts and texts. I intend to research how the methods

Mestrado e Doutorado em Linguística Aplicada pela UFBA (2003 e 2006). Professor no Departamento de Língua e Literatura Estrangeiras e na PGET (Pós-graduação em Estudos da Tradução) da Universidade Federal de Santa Catarina. Bolsista produtividade em pesquisa PQ 2 do CNPq. Florianópolis, Santa Catarina, Brasil. E-mail: sergioroma70@gmail.com 
of the so called science of the complexity could be applied to the study of the literary creative process. I consider writing as a kind of complex system characterized by three principles: complexity, instability and intersubjectivity. I suggest that the systemic principles applied to the study of literary manuscripts not only helps to pinpoint, study and process the laws and recurrences that support these processes, but they will also help to reveal the role played by creators.

KEYWORDS: Systemic principles. Literary manuscripts. Creative process. 


\section{LEITURA DA CRIAÇÃO: OS MANUSCRITOS LITERÁRIOS COMO UM SISTEMA COMPLEXO}

\section{BUSCANDO O NÃO-REPRESENTAVEL NA REPRESENTAÇÃO ARTÍSTICA}

O pintor Luca Giordano definiu o quadro Las Meninas, de Velásquez, como a teologia da pintura, mas aqui, ao invés, chamá-lo-ei de a teologia da criação artística, ampliando, dessa forma, o objeto de questionamento do pintor. Se, de fato, para Velásquez, o objetivo era mostrar ao observador os problemas específicos da pintura, no caso em questão, o quadro torna-se um meio plasticamente eficiente para ilustrar a questão da ambiguidade da representação artística, em geral, e do processo de criação de uma obra de arte.

O quadro, ambíguo e contraditório, já deu origem a várias e opostas interpretações mas, sem dúvida, aponta questionamentos fundamentais para a crítica artística e para a crítica literária contemporânea. Em realidade, a sintaxe visual do quadro sugere reflexões relacionadas com a questão da interpretação, da representação, da relação autor-obra e obra-leitor, e do processo de criação, dentre outras.

Pintado por Velásquez em 1656, o quadro se encontra hoje em Madrid, no Museu do Prado. No quarto retratado, se encontram nove figuras humanas e um cachorro. Da esquerda para a direita, vê-se, em primeiro plano: 
o próprio Velásquez, ao lado da tela, com pincéis e paleta; dona Maria Augustina de Sarmineto; a infanta Margarida; Dona Isabel de Velasco; a anã Mari Bárbola e o anão Nicolas Pertusato; mais atrás, dona Marcela de Ulloa e um homem de preto; ainda mais além, no limiar de uma porta entreaberta, encontra-se Jose Nieto Velásquez.

Ao olhar a cena com todos esses personagens, o espectador é levado a perguntar-se: afinal, qual dessas figuras é mesmo o sujeito da pintura? Pareceria um auto-retrato do pintor, porém, ao se observar bem, pode-se ver que todos os olhares, inclusive o do próprio Velásquez, mas excetuando o olhar do cão, apontam para uma direção, para um ponto externo ao quadro: na parede, ao fundo, abaixo de duas grandes telas, meio na sombra, nota-se um terceiro quadro que, graças ao jogo de reflexos, descobre-se ser, na realidade, um espelho. E dentro do espelho, se delineiam as figuras do soberano Felipe IV e da rainha Mariana. Velásquez teria, pois, representado a si próprio, no seu atelier, ao pintar um retrato dos soberanos espanhóis.

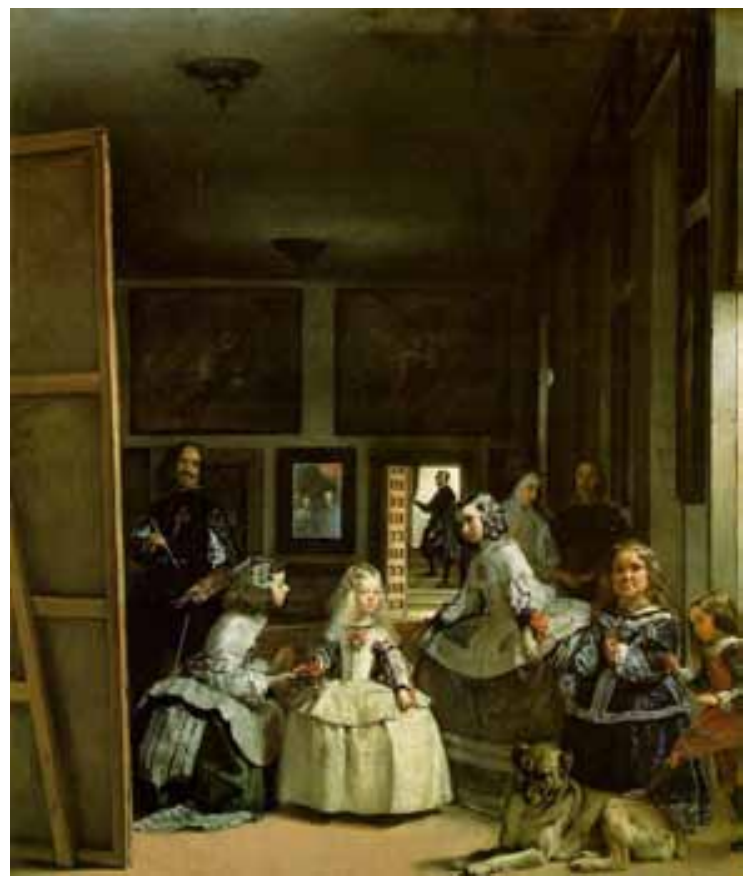

Figura 1 - Las Meninas de Velásquez 
Portanto, o espectador vê o artista empenhado no ato de pintar, mas não consegue enxergar o que ele está pintando porque, aos seus olhos, se apresenta somente o verso de uma grande tela. Pode-se observar o modelo que o pintor retrata somente graças a uma pálida imagem, que aparece refletida em um espelho distante. A posição de espectador acaba, enfim, coincidindo com aquela dos soberanos da Espanha, que o pintor retrata.

A partir dessa interpretação, o filósofo francês Michel Foucault (2001) propusera uma série de considerações sobre as relações entre realidade e representação, entre o visível e o invisível, entre a questão da presença e da ausência. Segundo ele, o espectador desse quadro só vê o avesso da tela trabalhada pelo pintor, verdadeiro mediador entre o visível, que é a obra representada e o invisível, que constitui a gênese da obra representada.

Enquanto o pintor é o rei entre essas duas dimensões incompatíveis - o que está representado e o processo de criação que levou àquela representação - o espectador, que não tem acesso à tela do pintor, "[...] percebe a trama, os montantes negros na horizontal e na vertical, o oblíquo do cavalete" (FOUCAULT, 2001, p. 195). Mas essa relação entre artista e intérprete não é tão unívoca; de fato, segundo Foucault, ela se caracteriza pela reciprocidade, considerando que os olhares do pintor e do público para o qual o autor aponta se sobrepõem, se cruzam e produzem "[...] toda uma complexa trama de incertezas, trocas e esquivas" (FOUCAULT, 2001, p. 195). Assim, ao olhar a obra, não existe somente o ponto de vista do pintor, mas uma pluralidade de pontos de vista, em que o público também participa da representação e do processo de recriação da obra, assim como de seu julgamento e interpretação. Mas os diversos olhares sobre a obra, porém, nunca são estáveis, bem como as interpretações que se sucedem, sempre mutantes:

Nenhum olhar é estável, ou melhor, no sulco neutro do olhar que atravessa a tela na perpendicular, o sujeito e o objeto, o espectador e o modelo invertem seu papel infinitamente. E a grande tela virada na extrema esquerda do quadro exerce ali sua segunda função: obstinadamente invisível, ela impede que jamais seja 
observável nem definitivamente estabelecida a relação dos olhares.

(FOUCAULT, 1965, p. 196)

Resumindo, neste quadro, convivem, no mesmo espaço, a representação de uma cena, o representado, o quadro, o representável, o processo criativo que aparece na tela do pintor e a percepção de tudo isso por parte do espectador envolvido também na representação pelo olhar do pintor. Deslocando essa análise para o plano mais geral da criação, poder-se-ia dizer que não existe, então, um objeto único e definível na criação artística, ou na pesquisa científica, mas há múltiplas interpretações e visões possíveis de um mesmo objeto ou de objetos diversos. Logo, não há, consequentemente, um olhar objetivo, mas uma pluri-subjetividade no âmbito de qualquer análise dos fenômenos artísticos; e percebe-se que não existe uma linearidade, mas sim a imprevisibilidade dos fenômenos, nunca iguais e estáveis. Assim, não existe uma obra de arte acabada e perfeitamente inteligível, mas o que se consegue são aproximações à representação de um processo de criação temporariamente acabado.

\section{A REPRESENTAÇÃO NA CRIAÇÃO LITERÁRIA}

Transpondo essas reflexões decorrentes do quadro de Velásquez para o âmbito da criação literária, percebe-se que, nem lá nem cá, existe linearidade, nem estabilidade na gênese de uma obra em prosa ou em versos, tampouco se pode considerá-la completamente inteligível e acabada.

Poder-se-ia, ao se tratar de criação literária, colocar, no lugar da tela de Velásquez, a obra de um autor que esteja sendo escrita, que seria o objeto de estudo da crítica literária. Poder-se-ia imaginar como seria o modus faciendi de um autor, ou seja, como ele se comportaria, ao ser focalizado no ato de escrever. O que ocorre é que, para o espectador-leitor, ao ler o livro acabado, ele chegaria apenas ao que equivaleria ao reflexo no espelho da obra de Velásquez; ou seja, à representação daquele processo de criação literária mostrado na tela, já que nunca se poderá desvelar, totalmente, o verso do livro, a sua gênese. 
Assim, como no caso do espectador do quadro, o leitor nunca poderá ter conhecimento completo da gênese, mas somente conseguirá acesso a um conhecimento parcial da obra. O mesmo aconteceria com o crítico-leitor que, ao analisar uma obra, terá como referência a obra acabada e não a sua configuração protéica em status nascendi.

No caso do crítico literário, contudo, ele pode até ter acesso aos bastidores da obra, cujos índices se pode observar nos rascunhos, nas anotações, enfim, nos manuscritos que o autor deixara. Ao registrar esses índices, é possível tentar reconstituir aquele processo misterioso da criação, e daí analisar a obra do ponto de vista privilegiado do seu criador, conseguindo, dessa forma, entrar na tela e dar uma espiada, ainda que furtiva, naquele trabalho singular, buscando depreender as leis que o norteiam. Essas leis, geralmente, podem ser depreendidas, ao se observar traços que se repetem na gênese, enfim, características que são reiteradas em determinado processo de criação. Contudo, durante muito tempo, a crítica literária considerara suficiente e, sobretudo, mais digna, a obra presumidamente acabada entregue pelo autor ao público, acreditando-se que fosse aquela a versão mais considerada pelo próprio autor.

A questão, porém, levantada na segunda metade do século XX pelos estudos genéticos, no âmbito da literatura, é que nem sempre a obra entregue ao público corresponde a uma versão considerada satisfatória pelo autor. $\mathrm{O}$ fato é que muitas variáveis intervêm na escolha da versão a ser publicada, e nem sempre, aliás, quase nunca, pode-se considerá-la como acabada só pelo fato de ter sido editada. De modo que, traçando uma analogia com o quadro de Velásquez, em apreço, pode-se imaginar que o estudioso que observa uma obra sob a ótica da Crítica Genética teria desejado entrar na tela do autor, ficar ao lado dele e acompanhar, através dos índices deixados no percurso de sua criação, aquele processo que levaria à versão considerada acabada, mas focalizando o seu interesse mais no processo que no produto considerado final.

Percebe-se, então, que o quadro Las Meninas, de Velásquez, pode ser considerado relevante no âmbito da pesquisa cientifica, não somente porque é uma pintura intencionalmente ambígua, e que assim se apresenta ao espectador, estimulando-o a fazer uma leitura do quadro, em níveis diferen- 
tes, mas também porque questiona os objetos e os sujeitos da representação. Portanto, a representação aparece não como um fenômeno singular, mas plural, em que intervêm muitas variáveis que, por sua vez, dão margem a várias interpretações. Considero, pois, que o autor e o espectador-intérprete não constituem dois pólos distintos e distantes, mas constituem categorias que podem se confundir, já que o leitor também é capaz de ser o autor, e o autor também, por sua vez, pode ser visto como leitor da obra, o que impossibilita apenas uma única interpretação. Logo, o quadro de Velásquez traz à tona questionamentos importantes e fundamentais, que caracterizam o novo paradigma do pensamento sistêmico contemporâneo, que fundamenta esta minha reflexão.

\section{UM NOVO PARADIGMA TRANSDISCIPLINAR}

Existem várias definições de paradigma, sendo que para Edgar Morin (1990), os paradigmas são princípios não evidentes que direcionam nossa visão de mundo e ajudam a organizar nosso pensamento. Segundo Capra (1982), paradigma constitui um conjunto de pensamentos, de percepções e valores, que direciona nossa visão da realidade e que se harmoniza com o modo como uma sociedade, inclusive a científica, se organiza. Segundo Esteves (2002), quando se fala de novo paradigma, refere-se a uma metodologia de pesquisa baseada em uma nova concepção do mundo e do trabalho científico:

Quando afirmo que o pensamento sistêmico é o novo paradigma ou a nova epistemologia da ciência, é o sentido de paradigma como crenças e valores dos cientistas que tomo como equivalente de epistemologia ou de quadro de referência epistemológico, no sentido de visão ou concepção de mundo implícita na atividade cientifica. De fato, os critérios de cientificidade compartilhados pelos cientistas, ou seja, os princípios diretores da investigação cientifica, refletem seu pa- 
radigma, sua epistemologia, sua visão de mundo, as crenças e os valores com que estão comprometidos. (ESTEVES, 2002, p. 43)

Para surgir um novo paradigma, esse deve passar a existir em relação a um outro paradigma, mais tradicional. Costuma-se chamar a ciência tradicional de ciência moderna, ou clássica, dos séculos XVII a XIX, enquanto que a nova ciência tem sido chamada de ciência pós-moderna, a do século XX, ou seja, a que Esteves (2002, p. 43) chama de "ciência novo-paradigmática emergente" ou "ciência novo-paradigmática".

Os pressupostos epistemológicos da ciência moderna, cartesiana e newtoniana eram fundamentalmente três, a simplicidade, a estabilidade e a objetividade:

1. O pressuposto da simplicidade acreditava que era possível separar um mundo complexo em partes, até se chegar aos elementos simples, necessários para se entender o todo. Dessa concepção decorreria a busca de relações causais lineares para se entender o fenômeno estudado;

2. o pressuposto da estabilidade do mundo e da crença na possibilidade de se conhecer os fenômenos acreditava que os fenômenos poderiam ser previstos e controlados;

3. o pressuposto da objetividade acreditava na possibilidade de se conhecer objetivamente o mundo tal como ele é. Daí a exigência da objetividade como um critério indispensável de cientificidade, bem como o esforço que se tem de fazer para eliminar a subjetividade do cientista para que se possa atingir uma versão única do conhecimento ou da verdade.

Uma consequência do primeiro princípio, o da simplicidade, seria a descontextualização do objeto de estudo, a assim chamada atomização ou disjunção das partes. Dessa atitude simplificadora, reducionista, decorre a compartimentalização do saber, a fragmentação das áreas do conhecimento cientifico, a multidisciplinaridade ou a pluridisciplinaridade.

$\mathrm{O}$ aspecto mais evidente do segundo princípio é o da previsibilidade dos fenômenos. A ideia é de que, já que conhecemos os princípios que regem a 
evolução do fenômeno estudado, podemos situar o seu estado inicial e, por consequência, prever, com segurança, o seu desenvolvimento, assim será possível controlá-lo e manipulá-lo. A consequência disso é que cada evolução incontrolada do sistema seria considerada negativa porque não haveria possibilidade de controlá-la. Segundo Esteves (2002), esta seria uma consequência do determinismo ambiental, que acredita "[...] que o observador, ou o cientista, ou aquele que conhece, pode manipular o sistema e que deve ser competente para fazê-lo" (2002, p. 88).

A consequência mais importante do terceiro pressuposto, o da objetividade, é de que o mundo que se almeja conhecer e estudar seria um mundo objetivo e independente de seu observador. Subjacente a esta concepção estaria a crença no realismo do universo, isto é, a ideia de que o mundo e tudo aquilo que nele acontece é real, existe independente de quem o descreve. Dessa concepção decorre, porém, uma consequência mais importante ainda: a de que existiria uma única descrição da realidade, já que haveria uma única realidade. $\mathrm{O}$ fato é que

[...] se existe uma realidade única deverá existir uma única descrição, uma melhor ou única versão, um uni-verso, que corresponda à verdade sobre essa realidade. E, como vimos, admite-se que só o expert no assunto conhece a verdade sobre seu objeto de estudo, por ter um 'acesso privilegiado' a esse aspecto da realidade. (ESTEVES, 2002, p. 90)

Sobretudo esse último princípio parece ter tido um eco no âmbito da hermenêutica literária e filológica medieval, bem como da moderna, quando se pensa no conceito de interpretação de textos, segundo o qual o crítico ou o hermeneuta deveria, ou poderia estabelecer o verdadeiro sentido e a verdadeira interpretação dos textos. Essa concepção foi, em seguida, desenvolvida pelo racionalismo moderno, sobretudo por J. M. Chladenius e F. D. Schleiermacher, que ampliaram a questão da hermenêutica dos textos bíblicos à análise de qualquer texto, sobretudo o literário. Assim como acontecia com os textos sagrados, a interpretação deveria visar a desvelar o presumido 
sentido oculto do texto analisado para que se pudesse reconstituir e entender as possíveis mensagens embutidas no próprio texto.

Segundo Chladenius, a questão que se deve especular não é tanto como entender uma obra, mas sim como interpretá-la. Antes disso, se deveria esclarecer o que significa interpretar um texto e qual seria a tarefa que haveria de caber à arte da interpretação: "[...] Interpretare altro non è che dunque dar in mano ai lettori i concetti dei quali essi lettori abbisognano per il perfetto intendimento di un luogo". ${ }^{1}$ Deve-se ainda esclarecer, segundo o filósofo alemão que, tanto a reconstrução do texto, quanto a sua explicação constituem sempre interpretações: filologia e hermenêutica são interdependentes.

A interpretação de um trecho pode ser, então, resolvida, segundo o filósofo, de duas formas: pelo conhecimento linguístico do filólogo e pela reflexão sobre pontos ambíguos, o que seria a tarefa do hermeneuta. Dever-se-ia levar em conta, ainda, segundo Chladenius, a intenção do autor, como se fosse possível saber que intenção seria essa:

Si può dunque in due diversi casi richiamarsi all'intenzione dell'autore, e ammonire il lettore a non perder di vista nessuno dei due: 1) quando costui alla lettura del luogo pensa qualcosa a cui l'autore non ha pensato, nel qual caso va oltre l'intenzione; 2) quando alla lettura del luogo non pensa qualcosa che pure l'autore ha pensato nel comporlo, nel qual caso il lettore ignora, o non coglie, l'intenzione dell'autore. [...] Ma quando non si va oltre l’intenzione, né la si ignora, allora s’intende l'autore. (CHLADENIUS apud SZONDI, 1992, p. 29-30)²

\footnotetext{
1 Todas as traduções de citações em línguas estrangeiras são de minha autoria quando não assinalado. Interpretar não é nada mais que, então, dar aos leitores os conceitos de que precisam para o entendimento perfeito de um trecho.

2 Pode-se fazer referência à intenção do autor de duas formas, e fazer com que o leitor as siga ambas: 1) quando este ao ler o trecho pensa em alguma coisa em que o autor não pensara, neste caso vai além da intenção; 2) quando ao ler o trecho não pensa em alguma coisa em que também o autor pensara ao compô-lo, neste caso o leitor ignora, ou não capta, a intenção do autor. [...] Mas quando não se vai além da intenção e não se ignora, então se entende o autor perfeitamente.
} 
Em outras palavras, na crença positivista a intenção do autor é algo que se deve interpretar e entender objetivamente, advindo daí a presumida existência de um discurso único e verdadeiro do autor. Caberia à crítica literária desvendar tal discurso, ao desmontar as estruturas linguísticas e não linguísticas que compõem o texto, alcançando então, a sua verdadeira e única interpretação, bem como a intenção do autor. Entendia-se por interpretação, na verdade, a conformação do texto a específicos cânones estéticos e morais.

Por outro lado, dentro do âmbito filológico e no domínio da hermenêutica religiosa, surge a necessidade de uma reconstituição e interpretação rigorosa dos textos sagrados. Somente com o surgimento da filologia humanística, a partir da experiência de Francesco Petrarca, leitor dos textos clássicos, até Coluccio Salutati, Leonardo Bruni e Poggio Bracciolini, é que a crítica literária, entendida como um conjunto de métodos e teorias historicamente determinado, que organiza os diferentes modos de abordagem do texto, toma consciência da sua especificidade e autonomia. Enfatiza-se, então, a importância de se reconstruir o texto, atentando para a sua identidade linguística e histórica. O pressuposto ideológico de toda a tradição filológica medieval e moderna era, então, buscar reconstituir o original, o que chamavam de uma versão melhor do texto literário, pressuposto que implicava na existência de uma única e digna versão do texto escrito pelo autor. Uma vez restabelecida a versão oficial, reconhecia-se a possibilidade de uma única e verdadeira interpretação do texto em questão, o que somente o filólogo ou o crítico, devido à sua autoridade e competência, poderia expressar.

Em contraposição ou em resposta aos três pressupostos que fundamentavam, como viu-se no parágrafo anterior, a epistemologia clássica ou moderna, podem-se distinguir, na contemporaneidade, graças às descobertas das teorias dissipativas da física, três eixos ou avanços que norteiam toda a pesquisa científica:

1. O pressuposto da complexidade, segundo o qual existem inter-relações entre os fenômenos do universo, os quais são intricados, em todos os seus níveis;

2. o pressuposto da instabilidade, segundo o qual o mundo não é, mas está em processo de vir-a-ser; disso decorre a indeterminação dos fenôme- 
nos e sua imprevisibilidade, sua irreversibilidade, com a consequente impossibilidade de controlá-los;

3. o pressuposto da intersubjetividade, segundo o qual se deve reconhecer que não existe uma realidade independente do observador.

[...] o conhecimento cientifico do mundo é construção social [...], o cientista coloca a 'objetividade entre parênteses' e trabalha admitindo autenticamente o multi-versa: múltiplas versões da realidade, em diferentes domínios lingüísticos de explicações.

(ESTEVES, 2002, p. 102)

Sem dúvida, o pressuposto epistemológico fundamental e central, no novo paradigma do pensamento sistêmico é o da complexidade. Fala-se muito em complexidade das sociedades, das organizações, das instituições, dos sistemas complexos, mas, de fato, não se trata de um conceito novo, embora o seu reconhecimento pela ciência date de pouco tempo. Cabe lembrar que, a partir dos anos 80 do século XX, começou-se a falar de complexidade com certa insistência, sobretudo, no âmbito da física e graças a autores como Edgar Morin que, em 1982 e 1983, publicou dois textos de referência sobre a teoria da complexidade: Ciência com consciência (1982) e O problema epistemológico da complexidade (1983), tendo também editado, em 1990, a Introdução ao pensamento complexo.

Deve-se, porém, ao físico Ilya Prigogine, com a publicação, em 1980, de From being to becoming. Time and complexity in the physical sciences, a maior sistematização teórica acerca dos sistemas complexos e simples, além da definição da lei da instabilidade. Sistema complexo é todo aquele composto por unidades que interagem entre si, sendo que os comportamentos imprevisíveis, desordenados e variados dessas unidades levam à instabilidade dos sistemas. E, segundo a abordagem sistêmica, não seria possível analisar um fenômeno isolado e fora do contexto de sistemas mais amplos, mas cada fenômeno deve ser estudado como um objeto pertencente a um contexto e dentro de sistemas mais amplos. Passar-se-á a indagar, então, em que condições o fenômeno ocorre e como está relacionado com os outros elemen- 
tos do sistema. Logo, o foco não estará mais no objeto em si, mas sim nas relações entre os elementos de um sistema. Reconhece-se que:

Contextualizar é reintegrar o objeto no contexto, é vê-lo existindo no sistema. E ampliando ainda mais o foco, colocando o foco nas interligações, veremos esse sistema interagindo com outros sistemas, veremos uma rede de padrões interconectados, veremos conexões ecossistêmicas, veremos redes de redes ou sistemas de sistemas.

(ESTEVES, 2002, p. 112)

Outra consequência do pensamento sistêmico, além da contextualização do objeto de estudo, é a capacidade de aproximar conceitos e disciplinas tradicionalmente opostas e que se encontravam em situação antagônica. A epistemologia complexa insiste, de fato, na necessidade de se estabelecer uma verdadeira interdisciplinaridade, que leve a uma comunicação entre instâncias até então separadas, dentro do âmbito do conhecimento.

Quanto ao histórico da noção de sistema e de sua evolução, considero aqui fundamental o biólogo austríaco Ludwig Von Bertalanffy, autor da Teoria Geral dos Sistema (1968). Primeiro, ele distingue duas tendências básicas dentro da teoria dos sistemas: a mecanicista, associada à Teoria Cibernética do matemático americano Norbert Wiener; e a organicista, associada à Teoria Geral dos Sistemas. A primeira seria mecanicista por causa da sua associação com as máquinas, ou com os sistemas artificiais, enquanto que a segunda se constituir como organicista pela sua associação com os organismos ou sistemas naturais, biológicos e sociais. A Teoria Geral dos Sistemas tinha como objetivo alcançar princípios interdisciplinares universais aplicáveis a todos os sistemas, em geral, e de qualquer natureza, seja física, biológica ou sociológica. Ambas as vertentes apontavam para teorias que desejavam transcender as fronteiras disciplinares e tiveram um papel fundamental para que se pudesse superar o pressuposto epistemológico da objetividade, assim contribuindo para a crença na possibilidade de uma construção intersubjetiva da realidade. Querendo definir a noção de 
sistema, Bertalanffy, no final dos anos 60, o reconhece como um complexo de elementos em interação, sendo a existência dessa interação e das relações entre seus componentes um aspecto central para identificá-lo. Constituiria, então, uma entidade, e não um mero conjunto de partes desligadas umas das outras. Consequentemente, para compreender o comportamento das partes que constituem um sistema, seria indispensável considerar as relações existentes entre elas, desde que cada parte está relacionada com as demais. Como lembra Esteves

[...] os sistemas não são inteligíveis por meio da investigação de suas partes isoladamente [...]. As relações são o que dá coesão ao sistema todo, conferindo-lhe um caráter de totalidade ou globalidade, uma das características definidoras do sistema [...]. A noção de sistema vem substituir a noção preliminar de gestalten - noção restrita às gestalten em física - referindo-se amplamente a qualquer unidade em que o todo é mais do que a soma das partes. (2002, p. 199)

Seria importante, ainda, ressaltar a noção de que um sistema é um todo integrado, cujas propriedades não podem ser reduzidas às propriedades das partes; além do mais, ainda que possa haver mudanças de membros que o compõem, não ocorrerá alteração das características do todo. Cabe também destacar que o sistema, por sua própria natureza, exercita coerções sobre o comportamento das partes e, por consequência, o grau de liberdade da ação de cada membro encontra-se limitado. Além disso, uma parte de um sistema não exibe as suas características em todos os sistemas, ou melhor, cada parte de um sistema exibe naquele sistema específico só algumas de suas características potenciais, por isso costuma-se dizer que o todo é menos que a soma das partes.

Por todas essas razões, torna-se evidente, a meu ver, o quanto é inadequado descrever os comportamentos possíveis de uma parte se não se levar em consideração as constrições que sofre por parte do sistema em que está inserido, como também é inútil querer descrever o sistema a partir somente 
das características específicas de um de seus membros. Esse tipo de abordagem, própria do paradigma tradicional da ciência moderna, acabou sendo superado pelo novo paradigma do pensamento sistêmico contemporâneo, que coloca o foco nas relações entre as partes para formarem um todo, uma só entidade. A existência dessas relações caracteriza o sistema como uma organização, ou melhor, uma organização hierarquizada e estratificada. De modo que, "Costuma-se então dizer que a natureza se constitui de sistemas dentro de sistemas ou de sistemas de sistemas" (ESTEVES, 2002, p. 205); ou, ainda, conforme Even-Zohar (1990) chamaria ,de polissistemas.

Existem, porém, dois tipos de sistemas: aqueles fechados e os abertos. Os sistemas abertos são aqueles que realizam uma contínua troca com o ambiente, que pode ser codificada (a chamamos de informação) ou não codificada (a que denominamos de ruído). A relação do sistema com essa informação nova caracteriza-o como fechado ou aberto. De fato, o sistema aberto é aquele que acolhe a informação nova, ou seja, que é sensível às variações do ambiente e que, consequentemente, consegue incorporar o novo input, ou melhor, a aprendizagem. Os sistemas abertos, por essa sua natureza, são chamados também de sistemas complexos.

\section{COMO FUNCIONA UM SISTEMA COMPLEXO}

Um dos princípios fundamentais da Teoria Geral dos Sistemas é o de equifinalidade, que significa que, nos sistemas complexos, o mesmo estádio final ou acabado se pode alcançar partindo de condições iniciais diferentes e por caminhos vários, o que torna impossível predeterminar como a meta será alcançada.

Todo sistema complexo, além disso, é regulado pela lei da circularidade, ou seja, há nele interações múltiplas e retroações, que não se inserem na lógica da causalidade linear - aquela em que, para uma causa específica corresponde um determinado efeito - mas agem segundo os princípios de uma causalidade recursiva. Em outras palavras, isso significa que "[...] parte do efeito (output) ou do resultado do comportamento/funcionamento do sistema volta à entrada do sistema como informação (input) e vai influir sobre o seu comportamento subsequente" (ESTEVES, 2002, p. 115). 
A recursividade se caracteriza por um processo em que os efeitos e os produtos são necessários ao próprio processo que os gera, e uma representação gráfica eficiente desse processo seria a forma espiral. A causalidade recursiva é um fenômeno complexo, desde que contém uma contradição: o produto é produtor do próprio processo que o produz. Outra contradição é que um sistema corresponde, ao mesmo tempo, a mais que a soma de suas partes e, por outro lado, também a menos que essa soma; ou seja, é mais porque do seu funcionamento decorrem qualidades que não existiam fora dele, e é menos porque o comportamento do sistema causa constrições que inibem qualidades pertencentes às partes.

Além disso, o sistema se baseia em outra lei importante, a da instabilidade, que gera a da desordem. É ainda à física que se deve a crítica da crença em um mundo estável, em que existem regularidades, e a afirmação da existência de um mundo perenemente instável, em contínua transformação e que se caracteriza por uma auto-organização constante. A física introduziu, pois, a noção de desordem, derrubando, dessa forma, o dogma de um mundo ordenado e estável. Claramente, uma vez que a física reconheceu a importância das noções de desordem e auto-organização, isso exerceu uma grande influência em todas as áreas do conhecimento.

Deve-se, sobretudo, a Prigogine (1980) e a suas pesquisas sobre as estruturas dissipativas, o estudo dos sistemas que funcionam longe do equilíbrio. Haveria, segundo ele, desvios e flutuações dentro do sistema, que influenciam o funcionamento do próprio sistema e a sua reorganização. Essa organização dentro da desorganização do sistema tornar-se-á importante, ao avaliarmos o processo criativo como um sistema complexo.

Sobretudo as noções de flutuação, desvio e ponto de bifurcação interessam aos fins de minha análise. As flutuações podem ser de origem interna ao próprio sistema, ou de origem externa, no caso provocadas pelo ambiente e, gerando, assim, em ambos os casos, uma perturbação no sistema. Uma flutuação surgida em uma parte do sistema é capaz de invadir o sistema todo e levar a um salto qualitativo, em qualquer ponto de bifurcação. Nesse ponto de crise, o sistema deixaria seu curso regular de funcionamento, optando, entre as alternativas possíveis, por um novo regime de funcionamento. Esse processo se chama de morfogênese ou gênese de novas formas a partir da instabilidade, 
a partir de um desvio, de uma desordem temporária. Seria nada mais que um processo de auto-organização. As escolhas feitas nos momentos de bifurcação geram, certamente, influências que têm um efeito sobre as escolhas do momento presente. Associo então o processo criativo a um sistema complexo em que o autor se encontra no meio de flutuações internas e externas ao próprio processo de criação, o que o leva a afastar-se do caminho planejado e o obriga, nos pontos de bifurcação, a fazer sempre novas escolhas. As rasuras constituem o testemunho desses momentos de crise no processo de criação.

Se, então, as escolhas prévias influenciam a estrutura, em um determinado momento, pode-se falar de determinismo estrutural. Quando isso ocorre, diz-se que "[...] o comportamento do sistema - sua escolha - é determinado pela estrutura que se estabeleceu através de sua historia" (ESTEVES, 2002, p. 125). No caso dos manuscritos de uma obra, por exemplo, as escolhas feitas pelo autor, ao longo de seu processo de criação, traçam o histórico de uma determinada estrutura criativa.

Duas consequências significativas da teoria da instabilidade para a pesquisa literária seriam, a meu ver, as seguintes: primeiro, o fato da instabilidade, que era vista somente como um desvio a ser corrigido, agora ser considerada como um pressuposto necessário para que o ruído provoque a ordem; segundo, o fato de que nos sistemas complexos se torna impossível estabelecer as condições iniciais e uma trajetória precisa de ação.

Igualmente impossível é, segundo a teoria sistêmica, categorizar o mundo, conforme fazia a física clássica, em sujeitos e objetos, desde que o fato de se estar observando um objeto já faz com que ele seja alterado. Estamos lidando, nesse momento, com o princípio da incerteza, segundo o qual não existe um ponto de vista que dê conta da totalidade do real. Por isso, propõe-se a questão da intersubjetividade, o que significa que o "[...] cientista conhecerá o fenômeno no estado em que escolher produzi-lo e descrevê-lo" (ESTEVES, 2002, p. 133).

Mas, não se deve esquecer que o surgimento de um novo paradigma cientifico implica e é acompanhado por um novo perfil de cientista ou de pesquisador. O cientista novo-paradigmático será aquele que, se apoiando nessa nova epistemologia, adotará “[...] uma nova forma de ver e de agir no mundo, baseada em sua única convicção possível: a da inexistência da 
'realidade' e da 'verdade”' (ESTEVES, 2002, p. 174). Esse especialista terá uma preocupação ética ao se interrogar constantemente acerca de seu trabalho, acerca das alternativas que estará abrindo com suas ações, acerca da sua crença em que o sistema seja auto-organizador, ou ainda, que não se pode direcioná-lo. Tal especialista deveria levar em consideração as conexões intersistêmicas e as repercussões que, provavelmente, suas ações terão em outros pontos da rede de sistemas ou polissistemas. O que ocorre é que:

Essa preocupação ética do profissional fará com que jamais tente impor ao sistema aquelas soluções que $a$ priori poderia considerar serem as melhores [...] lembrando-se de que o que cada um diz fala mais de si do que da coisa observada.

(ESTEVES, 2002, p. 178)

\section{O PROCESSO CRIATIVO COMO UM SISTEMA COMPLEXO}

Parece-me necessário agora indagar como os métodos da assim chamada ciência da complexidade ou do pensamento da complexidade ou do novo paradigma sistêmico podem ser aplicados aos estudos do processo de criação literária. Apesar de hoje se criticar o paradigma científico, que é visto como reducionista e que, como vimos, se baseava nos três princípios epistemológicos da simplicidade, da ordem e da regularidade - em contraposição à complexidade, desordem e caoticidade - começou-se a observar que pode haver comportamentos não previsíveis a partir de sistemas determinísticos, chegando-se, assim, à definição do que seriam sistemas complexos.

A etapa seguinte consistiria em aproximar conceitos e métodos das ciências da natureza a problemas das humanidades. Nos últimos anos, houve então a tentativa de fazer pesquisas, associando modelos que aplicassem os princípios da complexidade à literatura. Na minha pesquisa, pretendo relacionar o pensamento da complexidade a estudos de processos criativos, especialmente relacionados com o processo tradutório.

Se, como afirmado anteriormente, o sistema aberto ou complexo é ca- 
racterizado pela inter-relação de elementos que compõem uma unidade, ou por um conjunto de partes que compartilha algo em comum, e se esse sistema troca informações com o meio ambiente que o cerca, buscando a permanência e a estabilidade, mas possuindo uma tendência à desordem e à imprevisibilidade, então o processo criativo comporta-se como um sistema complexo. Trata-se de um

[...] sistema, diga-se de passagem, portador de altíssima complexidade, através da qual uma diversidade de elementos mobilizam-se, tencionam-se, acomodam-se e muitas vezes se dissipam. Participando de uma tendência de cunho geral, os elementos do processo partilham um objetivo comum, a construção de algo no seio da linguagem, sistema com o qual tem participação e intervenção direta.

(HENN, 1998, p. 202)

O sistema criativo é, então, um sistema dinâmico e aberto, não linear. Por isso se aproxima dos sistemas naturais, que revelam fenômenos não previsíveis e caóticos. Essa aproximação, segundo Fiedler (1995), entre os sistemas naturais e os literários, acontece mediante três modelos de pensamento da complexidade: caos determinístico, estruturas dissipativas e complexidade a partir do ruído. Fiedler, baseando-se nos três modelos referidos, tenta uma aproximação entre complexidade e literatura, considerando o macrossistema representado pelas relações entre autor-texto-leitor e dividindo-o em dois subsistemas: o processo de criação, ou seja, a relação autor-texto; e o processo de leitura, ou seja, a relação leitor-texto, levando, porém, em conta que no processo de criação o autor é também o primeiro leitor de sua obra. Tanto o macrossistema, quanto os dois subsistemas, são sistemas complexos, abertos, longe do equilíbrio, não lineares e em presença de ruído.

O primeiro modelo, o do caos determinístico, ocorre, sobretudo, em sistemas não lineares, que são caracterizados por uma dependência às condições iniciais; ou melhor, trata-se de sistemas em que, por sua própria dinâ- 
mica, podem aumentar algumas variações das condições iniciais e ocorrer um comportamento imprevisível que possui, de certa forma, suas próprias regras de funcionamento, mas não facilmente detectáveis naquele caos inicial. Deve-se entender a noção de caos como informação extremamente complexa e não como ausência de ordem. Por consequência, aqueles sistemas que apresentam tendência ao caos, possuem uma grande gama de informações. Uma das implicações mais importantes dessa noção de caos é a crença ilusória de que se possa estudar um sistema isoladamente e sem levar em conta o seu contexto, pois tal abordagem desconsidera toda uma série de variáveis, perturbações, influências, que os vários sistemas externos, ou polissistemas acolhem.

No que diz respeito a esse primeiro subsistema do processo de criação literário, isto é, à relação autor-texto, Fiedler destaca a possibilidade de pequenas variações na caracterização das personagens e na relação entre as personagens de um romance, ou "[...] nas escolhas lexicais, nas impressões do mundo sobre o autor, na sua memória e no seu estado de espírito no processo de escritura, na situação econômica e política circundante à produção da obra, etc." (1995, p. 38). Tudo isso pode afetar, de forma significativa, não somente a elaboração do texto, mas o seu resultado final, isto é, a obra considerada terminada, bem como o processo de releitura que o autor-leitor faz, a cada etapa do processo. Essa dinâmica destaca um princípio interno da produção artística, que Fiedler chama de dependência em relação às condições inicias; existem, porém, além das condições iniciais, presentes no início da elaboração do texto, as condições iniciais locais, isto é, aquelas decorrentes das escolhas feitas ao longo do processo de criação textual.

Há, pois, dois planos de ação que se sobrepõem: por um lado, as condições iniciais, que dão uma estrutura provisória e desejável à obra a ser composta; por outro, as condições locais, ou seja, as escolhas decorrentes de mudanças e influências endógenas ou exógenas ao processo criativo, que modificam aquelas condições iniciais: "A cada etapa do processo de criação textual, o autor se policia, consciente ou inconscientemente, descartando escolhas que possam desviar muito a narrativa do desejado." (FIEDLER, 1995, p. 39). Essa dependência, então, às condições iniciais, caracteriza a dinâmica e a natureza do sistema criativo, que pode ser somente controlada pelo autor. 
Porém, apesar dessa dependência às condições iniciais, as diferentes versões de um texto artístico e a própria versão final devem ser consideradas como estruturas auto-organizadas em um sistema aberto, sendo que as variantes do texto possuem as características dos sistemas fora do equilíbrio. Assim como nas estruturas dissipativas, o texto vai se estruturando como se cada parte ou etapa ou variante fosse informada do estado global do sistema como um todo, e o texto provisoriamente final é o resultado de desorganizações seguidas de novas reorganizações, cada vez em níveis de complexidade mais elevados.

O segundo modelo é o das estruturas dissipativas ou dos sistemas auto-organizados, teoria que, como já mencionado, foi desenvolvida principalmente pelo físico Ilya Prigogine, e segundo a qual

[...] As estruturas dissipativas são fenômenos de criação de ordem longe do equilíbrio em sistemas não lineares abertos. Essas estruturas ocorrem em sistemas que necessitam um grande número de variáveis para descrevê-los [...] sistemas imersos num meio dissipativo na presença de ruído [...]. O processo de auto-organização é determinado sobretudo pelas propriedades do próprio meio [...].

(FIEDLER, 1995, p. 35)

Nesse sistema, que mantém uma troca constante com o contexto, aparecem padrões que se repetem e que atuam dentro de uma relação de trocas com a parte externa do sistema; "[...] ele se estrutura como se cada sua parte fosse 'informada' a respeito do estado global” (FIEDLER, 1995, p. 35). No que diz respeito ao segundo subsistema que caracteriza o sistema criativo, isto é, a relação leitor-texto, Fiedler destaca o fato de que o leitor vivencia, ao se aproximar do texto, a complexidade como desordem ou ruído. Em outras palavras, os textos são, na definição de Fiedler, canais ruidosos, isto é, canais de comunicação ou de transmissão de significados ambíguos ou imperfeitos: "Ruído, interno ou externo ao texto, pode levar à emergência de novos níveis de significado não previsíveis do ponto de vista lingüístico 
ou das convenções do gênero, nem sujeitos ao julgamento ou elaboração do autor" (FIEDLER, 1995, p. 40). Isso significa que, em literatura, o significado e a informação podem surgir da interação com a desordem. Paradoxalmente, em um contexto ruidoso ou de desordem, em literatura, também, variantes não explicáveis tornam-se geradoras de um novo nível de significação, levando à criação de um novo contexto mais informativo que ruidoso. Neste caos, também há dependência sensível às condições iniciais de leitura:

Com efeito, pequenas nuances ou estímulos que o leitor eventualmente absorve do meio circundante ou da sua memória podem afetar de maneira significativa a particular escolha que esse fará no conjunto daquelas compatíveis com os vínculos impostos pelo texto, repercutindo-se essa escolha na emergência do significado.

(FIEDLER, 1995, p. 41)

Afinal, afirmaria que este subsistema, assim como o primeiro, comporta o surgimento de novos significados e informações a partir do ruído, com o aparecimento de outras estruturas auto-organizadas a cada nível de leitura, e dependência das condições inicias. Esse processo se caracteriza por ser inacabado, pois a cada leitura, são geradas novas interpretações que levam ao surgimento de múltiplos significados.

O terceiro, a auto-organização e complexidade a partir do ruído, atribui ao observador e, no caso do texto literário, ao leitor, um papel fundamental na definição dessa complexidade, considerando que se deve dar mais ênfase à relação entre sujeito e objeto do que à própria estrutura do objeto estudado: "Nessa perspectiva, a criação de complexidade se nutre de desordem (ruído). O aleatório passa então a ser parte integrante da organização" (FIEDLER, 1995, p. 36). Ao falar em literatura, entendo por ruído o uso de uma sintaxe marcada por licenças poéticas, bem como o uso de neologismos, dificilmente compreensíveis pelo leitor. Portanto, um grau maior de ruído pode dificultar não somente a elaboração do texto, mas também a sua leitura.

Resumindo, considerando as propriedades dos três modelos, podem-se destacar as seguintes diferenças: no modelo caótico determinístico, a dinâ- 
mica do sistema aumenta pequenas diferenças das condições iniciais; no modelo das estruturas dissipativas, o estado final do sistema não depende das condições iniciais; finalmente, no terceiro modelo, na complexidade a partir do ruído, a evolução das condições iniciais depende do observador e do nível de observação.

O texto é o resultado, então, desse macroprocesso complexo, que é influenciado pelo mundo e que, por sua vez, o influencia. Nesta análise, considero o mundo representado pela sociedade e pela língua por ela utilizada, pelos padrões literários e estéticos de uma determinada cultura; ou pelos padrões editoriais, como partes integrantes do sistema, dentre uma rede maior de sistemas, que se chama de polissistema. É necessário, a fim de se entender esse complexo processo de inter-relações, conhecer cada subsistema que compõe tal conjunto.

\section{INSTABILIDADE E ESTABILIDADE NA ESCRITA}

Philippe Willemart (1996), também inspirado na teoria do químico Ilya Prigogine, propõe adotar o novo paradigma da instabilidade-estabilidade para analisar os manuscritos literários, buscando, dessa forma, construir uma ponte entre as teorias dissipativas da física e a crítica literária:

[...] a estabilidade e/ou instabilidade. Esta permuta sublinha que não há oposição nítida nem separação entre os dois termos, mas, pelo contrário, a convivência dos dois estados e a geração de um pelo outro. Durante uma zona de estabilidade no manuscrito, o escritor satisfeito com uma página ou com uma versão do livro, publica e passa adiante. Mas de repente, durante uma outra releitura, surge uma bifurcação imprevista e perturbadora que transforma o quadro e obriga o escritor a inventar uma nova página ou uma outra versão.

(WILLEMART, 2000, p. 411) 
No seu artigo Instabilidade e estabilidade dos processos de criação no manuscrito literário (1996), ele compara as palavras de uma obra literária a moléculas que se reorganizam, dando vida a um produto sempre diferente. $\mathrm{O}$ foco não estaria mais no escritor, agente consciente da escrita, mas sim, no scriptor, ou seja, o sujeito inconsciente da escrita, aquele que simplesmente grava as combinações que as próprias palavras sugerem; não existiria, então, uma relação de causa-efeito entre autor-obra:

[...] Mallarmé já questionava a noção de causa na escritura [...]. Ele preferia atribuir o produto da escritura ao efeito das palavras dispostas na página branca e minimizava o escritor, sua história e sua vida como causa primordial. Ignorava, em outras palavras, o biografismo e a relação vida-obra [...].

(WILLEMART, 1996, p. 27)

Willemart quer, em outras palavras, reafirmar a autonomia da palavra poética que domina o papel elocutório do poeta. Essa autonomia seguiria, porém, leis precisas e próprias de um sistema aberto e complexo; as palavras teriam, na opinião do geneticista francês, energia e velocidade ao se deslocarem no poema, demonstrando a sua instabilidade. Assim como as partículas colidem no espaço originando novas combinações e novos elementos, da mesma forma, as palavras se encontram e se defrontam no espaço limitado de um verso, desencadeando novos significados e sentidos, através até de figuras retóricas, como a metonímia e a metáfora: "São maneiras usadas pela língua para evoluir e inovar, o que ressalta a importância dos poetas numa cultura" (WILLEMART, 1996, p. 29).

O estudo dos manuscritos literários destacaria a importância do scriptor, isto é, a instrumentalidade do escritor e a supremacia da escritura. Apesar, então, de se estar lidando com um sistema criativo, que tem suas próprias leis, não se pode excluir a intervenção do acaso nesse processo. Assim, é possível detectar as leis que produzem esses encontros de palavras, mas nunca se poderia prevê-las: “[...] há mil possibilidades na construção de um verso [...] quantidade infinita de variáveis, assim o poema nunca poderia ser pro- 
gramado e determinado" (WILLEMART, 1996, p. 30). Logo, até o próprio autor do poema nunca poderia prever o resultado desses embates de palavras, que acontece no espaço limitado da folha branca.

Willemart prefere, então, falar sobre o processo da escrita como um sistema regulado pelas leis da instabilidade e da estabilidade. De fato, determinismo e movimento aleatório conviveriam, um gerando o outro, ou um elemento que escapa ao previsível gerando bifurcações, possibilidades, enfim, uma desordem que sempre se reorganiza em nova ordem:

[...] as 24 letras \{um sistema a princípio estável\}, ${ }^{3}$ as palavras [...] mergulhadas no ato poético, adquirem ou readquirem uma instabilidade e uma imprevisibilidade exemplar. O processo escritural ou artístico tem a capacidade de eliminar a estabilidade das letras e das palavras [...] permite um retorno à sua própria historia e a recuperação de uma instabilidade criadora. As colisões provocadas no verso provocam perturbações que impossibilitam o domínio do processo e tornam imprevisíveis as conseqüências.

(WILLEMART, 1996, p. 34)

Em suma, o pensamento sistêmico aplicado ao estudo dos manuscritos literários ou aos manuscritos de quaisquer processos de criação artística, não somente permite localizar, estudar e processar as leis e recorrências que regem tais processos, mas, sobretudo, ajuda a destacar o papel de seus atores; sejam esses, atores ou criadores, artistas, tradutores, poetas ou músicos.

\section{REFERÊNCIAS}

BERTALANFFY, Ludwig. Von. Teoria geral dos sistemas. Petrópolis: Vozes, 1968.

3 O comentário é nosso, utilizando-se o sinal \{\} para indicar quaisquer comentários do pesquisador que venham a ser inseridos no texto citado. 
CAPRA, Fritjof. O Ponto de Mutação: A Ciência, a Sociedade e a Cultura Emergente. 25. ed. São Paulo: Cultrix, 1982.

ESTEVES, María José De Vasconcellos. Pensamento Sistêmico o novo paradigma da ciência. Campinas (SP): Papirus, 2002.

EVEN-ZOHAR, Itamar. Polysistem Studies. Poetics Today. International Journal for Theory and Analysis of Literature and Communication. The Porter Institute for Poetics and Semiotics, 1990, v. 11, n. 1, 246p.

FIEDLER, Ferrara, Norman O fenômeno da complexidade (palestra). [s.l.], 1995. p. 1-10.

FOUCAULT, Michel. As damas de companhia. In: MOTTA, M. Barros da (Org.). Foucault. Estetica: literatura e pintura. Musica e cinema. Trad. Ines Autran Dourado Barbosa. Rio de Janeiro: Forense Universitaria, 2001. p. 194-209.

HENN, Ronaldo. Organização e Caos. Manuscrítica- Revista de Crítica Genética. São Paulo, APML, n. 7, p. 197-209, 1998.

MORIN, Edgar. Ciência com consciência. Lisboa: Publicações Europa-América, 1982.

MORIN, Edgar. O problema epistemológico da complexidade. Lisboa: Publicações Europa-América, 1983.

PRIGOGINE, Ilya. From being to becoming. Time and complexity in the physical sciences. Nova York, W.H. Freeman \& Co, 1980.

SZONDI, Péter. Introduzione all'ermeneutica letteraria. Torino: Einaudi, 1992. 
WILLEMART, Philippe. Instabilidade e estabilidade dos Processos de Criação no Manuscrito Literário. Manuscrítica- Revista de Crítica Genética. São Paulo, APML, n. 6, 1996, p. 21- 43.

WILLEMART, Philippe. O operador na escritura. In: GAMA, Albertina. Ribeiro da; TELLES, Célia Marques; ALVES, I. I. Duarte (Org.). Memória cultural e edições. Salvador: EDUFBA, 2000. p. 411-424. 